\title{
Retrospectiva comercial mexicana: del TLCAN al T-MEC
}

Retrospectiva do comércio mexicano: Do NAFTA ao T-MEC

Mexican trade retrospective: From NAFTA to USMCA

\author{
Hector Hugo Maldonado Salinas \\ hector.mldo@gmail.com \\ Universidad Autónoma de Nuevo León - México \\ https://orcid.org/0000-0003-0386-4253 \\ Gustavo Daniel Ortiz Téllez \\ gustavo.ortiz.tellez@gmail.com \\ Universidad Autónoma de Nuevo León - México \\ https://orcid.org/0000-0002-4340-2232
}

\section{RESUMEN}

El presente ensayo tiene como objetivo analizar y describir fragmentos históricos del desarrollo comercial mexicano, así como los factores que evidencian la interdependencia asimétrica con los Estados Unidos pese a la diversificación comercial mexicana al resto del mundo. El presente ensayo estriba en tipo cualitativo, siendo no experimental, enfocándose en la recolección de documentos históricos y científicos para su análisis y descripción. La primera fase documental describe y analiza la situación comercial y económica de México durante los últimos 25 años, la negociación y consolidación de México con la creación de nuevos tratados comerciales, la segunda fase se enfoca principalmente analizar los factores de la competitividad y la inversión extranjera directa además reseñar una recapitulación de los eventos en que repercutieron el cambio de poder ejecutivo en Estados Unidos en 2017 que derivo en la renegociación y en la modificación del tratado de libre comercio en 2018 y como este impacto a México.

Palabras clave: Comercio Internacional, Competitividad, Tratado de Libre Comercio, México, Estados Unidos

\section{RESUMO}

O presente ensaio tem como objetivo analisar e descrever fragmentos históricos do desenvolvimento comercial mexicano, assim como os fatores que evidenciam a interdependência assimétrica com os Estados Unidos, apesar da diversificação comercial mexicana com o resto do mundo. O presente ensaio é de natureza qualitativa, não experimental, centrando-se na compilação de documentos históricos e científicos para a sua análise e descrição. A primeira fase documental descreve e analisa a situação comercial e econômica do México durante os últimos 25 anos, a negociação e consolidação do México com a criação de novos acordos comerciais. A segunda fase concentra-se principalmente na análise dos fatores de competitividade e investimento estrangeiro direto. Além de analisar uma recapitulação dos eventos que tiveram impacto na mudança do poder executivo nos Estados Unidos em 2017 que levaram à renegociação e modificação do acordo de livre comércio em 2018 e como isso impactou no México.

Palavras-chave: Comércio Internacional, Competitividade, Acordo de Livre Comércio, México, Estados Unidos

\begin{abstract}
The present essay aims to identify and report historical fragments of Mexican commercial development, as well as the factors that show the asymmetric interdependence with the United States despite the Mexican commercial diversification to the rest of the world. The present essay is of a qualitative type, being non-experimental, focusing on the collection of
\end{abstract}


historical and scientific documents for their analysis and description. The first documentary phase describes and analyzes the commercial and economic situation of Mexico during the last 25 years, the negotiation and consolidation of Mexico with the creation of new trade agreements, the second phase focuses mainly on analyzing the factors of competitiveness and foreign investment. Direct also review a recapitulation of the events that affected the change of executive power in the United States in 2017 that led to the renegotiation and modification of the free trade agreement in 2018 and how this impact on Mexico.

Keywords: International Trade, Competitiveness, Free Trade Agreement, Mexico, United States

\section{INTRODUCCIÓN}

La caída del muro de Berlín en 1989 y el posterior colapso de la Unión de Repúblicas Soviéticas Socialistas en 1991 trajo como repercusión un cambio en el Sistema Internacional, a partir de ese momento las prioridades de la agenda internacional de los Estado-Nación cambiaron, la prioridad paso de ser un conflicto ideológico entre dos bloques (capitalismo-comunismo) para ahora enfocarse en tener un comercio exterior sólido y economía creciente.

Para lograr una economía y comercio creciente los Estados comenzaron a optar por integrar sus economías en bloques regionales, de esta manera en 1992 se firma el Trato de Libre Comercio entre México, Estados Unidos y Canadá (TLCAN), dicho tratado entra en vigor el primero de enero de 1994, siendo el TLCAN la piedra angular en el comercio exterior y antesala de la Organización Mundial de Comercio en 1995 que tomó como ejemplo en su visión los principios rectores del TLCAN.

La entrada en vigor del TLCAN fue una herramienta que permitió a México impulsar su economía y acoplarla a las tendencias y necesidades que demandó la nueva era de la Globalización, sin embargo; las diferencias tanto sociales, económicas y comerciales eran colosales comparando la competitividad de la economía Mexicana con la Estadounidense lo que ha provocado desde entonces debates entre si fue lo correcto o no para México y como consecuencia se comenzaron a presentar ideas que puedan reformar y ayudar a la economía mexicana para equilibrar esa tendencia desigual existente.

En 2018 después de casi un cuarto de siglo de existencia del TLCAN, los gobiernos de los tres países que conformaron el acuerdo acordaron reestructurarlo dejando sin vigor al TLCAN sustituyéndolo por el Tratado entre México, Estados Unidos y Canadá (T-MEC), dicho tratado introdujo la regulación energética, comercio electrónico y medio ambiente, además de estructurar los apartados del sector automotriz, textil, maquilador y manufacturero. El T-MEC entro en vigor el primero de Julio de 2019, sujeto a una revisión periódica cada seis años, con el fin de garantizar la medición de resultados y el beneficio de cada una de sus partes.

Los últimos años del TLCAN dejaron como evidencia la interdependencia asimétrica entre ambas naciones, la enorme desigualdad competitiva y la falta de desarrollo en diversos rubros a raíz de factores precarios que con apoyo tanto del sector público como privado podrían mejorarse para lograr que los sectores existentes puedan impulsarse y lograr por parte del lado mexicano una mayor competitividad frente a Estados Unidos y Canadá.

La responsabilidad de la competitividad no sólo recae o es competencia de las empresas como lo fue en el pasado, sino que cada vez en mayor medida, depende de políticas públicas que creen el marco y las condiciones necesarias para el desarrollo en un nivel competitivo, sin embargo; es necesario e importante llevar a cabo un análisis y presentar propuestas que ayuden a reducir esta desigualdad competitiva en la relación bilateral para poder hacer constructivismo en las áreas de 
oportunidad pues es de suma importancia el imperativo acoplamiento de México hacia las tendencias globales.

El ensayo tiene como objetivo analizar y describir fragmentos históricos del desarrollo comercial mexicano comenzando desde su ingreso al GATT, hasta la transformación del Tratado de Libre Comercio de América del Norte (TLCAN) al Tratado de México, Estados Unidos y Canadá (TMEC), así como los factores que evidencian la interdependencia asimétrica con los Estados Unidos pese a la diversificación comercial mexicana al resto del mundo, esto con el fin de demostrar como hipótesis que en efecto desde el ingreso de México al GATT y después al TLCAN ha habido un cambio significativo positivo en el modelo económico y comercial mexicano.

Para llevar a cabo este ensayo se realizó una búsqueda exhaustiva de documentos científicos e históricos, posteriormente se analizó y argumentó las aportaciones de dicha información y proceder con propuestas que ayuden a impulsar la competitividad de México.

Así, este ensayo está conformada por cuatro apartados, el primero de ellos funciona como una introducción al desarrollo comercial mexicano en los años ochenta, en el cual se exponen los hechos que resultaron en la creación del TLCAN, el segundo apartado expone la geopolítica mexicana, las oportunidades que han traído esta posición geográfica y se evidencia la interdependencia asimétrica enfocándose en la competitividad y la inversión extranjera directa (IED), el tercero de ellos abarca la era del proteccionismo estadounidense (2017-2021) y los riesgos que sobre llevo México y sus exportadores durante ese periodo, por último en las consideraciones finales se dan las propuestas que podrían ayudar en diversificar la economía mexicana al exterior para no volver a repetir las experiencias de la proteccionismo estadounidense.

\section{PROCEDIMIENTO METODOLOGICO}

El presente ensayo es de carácter documental y exploratorio abarcando principalmente la recolección de literatura científica para la realización del mismo. El diseño del presente ensayo documental y exploratorio es: no experimental y descriptiva, debido a que se pretende analizar, observar y describir la información sin algún tipo de práctica o técnica que altere los resultados dados de manera natural y exploratoria, debido a que los resultados de este ensayo pretenden ser generales para que en el futuro puedan ser utilizados como punto de partida para futuras investigaciones con objetivos más concretos.

\section{FUNDAMENTO TEÓRICO}

\subsection{Semillas de una crisis}

México sufrió un profundo estancamiento económico en los años ochenta a raíz de la crisis de la deuda y la nacionalización bancaria repercutiendo en una caída en el PIB per cápita, en los salarios 
reales y en la productividad. Como consecuencia de ello se dieron cambios estructurales profundos que transformaron al país, siendo la privatización de empresas estatales, la reprivatización de la banca y la apertura comercial internacional los más relevantes.

A partir de esta crisis se comenzó a reemplazar el modelo de sustitución de importaciones, para dar paso a una política económica que contemplo la desestatización de la economía y una apertura comercial que tuvo como primer paso el ingreso de México al Acuerdo General de Aranceles Aduaneros y Comercio (GATT, por sus siglas en inglés) e incluyo a la postre la firma del Tratado de Libre Comercio de América del Norte, TLCAN.

El proceso de apertura comercial, que inició con la incorporación en 1986 al Acuerdo General sobre Aranceles Aduaneros y Comercio (GATT, 1948), desde 1995 la Organización Mundial del Comercio, (OMC) y que fue profundizado con la firma del Tratado de Libre Comercio de América del Norte (TLCAN) en 1994, se ha visto reflejado en flujos de exportaciones que son siete veces superiores a los de 1994.

De acuerdo con Schiavon \& Figueroa Fischer (2019) con las reformas económicas iniciadas en la década de 1980 y el cambio de modelo de desarrollo hacia la promoción de la inversión extranjera directa y las exportaciones, el comercio internacional del país (importaciones más exportaciones) represento en el año 2017 más de tres cuartas partes del PIB (77.57\%), es decir, uno de los principales motores económicos nacionales. Junto con el turismo, proporciona trabajo de manera directa e indirecta a millones de mexicanos.

\subsection{Geopolítica mexicana}

México es un país diverso, siendo la onceava población a nivel mundial de 194 países, es la doceava economía del mundo por "PPPs" Purchasing Power Parity (paridad de poder adquisitivo) además de contar con la ventaja comparativa de las pertenencias múltiples. La posición geográfica mexicana le da un carácter norteamericano, centroamericano, latinoamericano, caribeño además de poseer vínculos históricos con Europa, es parte de Asia pacifico (APEC) y de la Alianza del Pacifico, miembro del G20, estos lazos existentes podrían permitir la consolidación y diversificación de la economía mexicana.

La nación posee un vasto acceso al comercio internacional a través de sus litorales, lo que les permite el acceso marítimo inmediato a los otros continentes del planeta. El país ha sido capaz de establecer un gran número de acuerdos comerciales que facilitan la entrada de sus productos a un amplio mercado contando con 13 Tratados de Libre Comercio con 52 países siendo México uno de los países con una apertura global significativa en el comercio internacional.

Por otro lado, el cambio en la arquitectura geopolítica representó una oportunidad para los países latinoamericanos, las nuevas dinámicas de crecimiento económico y las reformas en la política interna, benefician a las naciones desarrolladas, abriendo una ventana en el escenario internacional para que los países emergentes como México y Brasil puedan tomar un papel destacado.

Las circunstancias históricas, políticas, sociales y culturales confluyen en los retos y posibilidades para el nivel de desarrollo en el caso mexicano, la planeación del desarrollo está 
encuadrada por el contexto Internacional que se vive y por la historia y la evolución reciente de México, en síntesis, la proyección internacional es la piedra angular de México con Responsabilidad Global y la ubicación geográfica del país es una de las ventajas comparativas y competitivas de la nación.

\subsection{Ventajas y áreas de oportunidad de México}

A pesar de la ubicación geográfica mexicana, la red de intercambio comercial mexicana la diversificación comercial sigue siendo precaria, el comercio internacional se concentra principalmente en los Estados Unidos, en base a los datos de Statista (2020) en 2019, Estados Unidos fue el destino más importante de las exportaciones mexicanas de bienes, las exportaciones a Estados Unidos representaron cerca del $78 \%$ del total. Por su parte, Canadá ocupó la segunda posición, con solamente un 3\% de las exportaciones de bienes provenientes del país latinoamericano. (Ver gráfica 1)

Gráfica 1. Distribución porcentual del valor de las exportaciones de bienes de México en 2019, por pais destino.

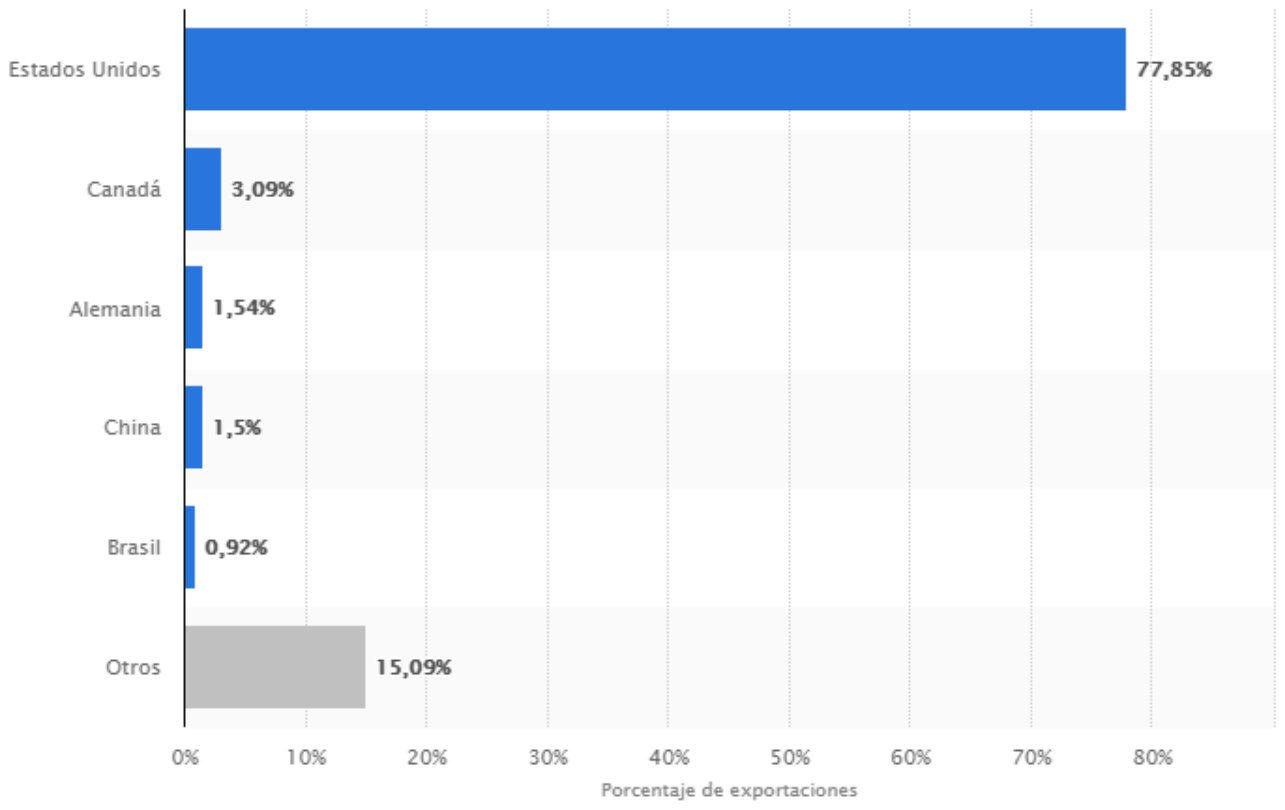

Fuente y grafica tomados de: Statista (2020).

De acuerdo con Duarte (2019) se ha presentado un aumento de la dependencia de la economía mexicana a la estadounidense, lo que en un principio los gobiernos federales pretendían evitar con la diversificación de relaciones comerciales, los indicadores oficiales del INEGI (2019) indican que, desde el primero de enero de 1994 hasta noviembre de 2019, el saldo de la balanza comercial del país 
ha sido mayoritariamente negativo para la economía mexicana, para 2019 el porcentaje de las exportaciones dirigidas hacia los EUA se encuentra entre el 76- 78\%.

\subsection{Consolidación de tratados y su productividad}

La consolidación de tratados no ha hecho mayor efecto en la toma de decisiones de los exportadores mexicanos para apuntar a otros destinos, en la práctica para los exportadores mexicanos, Estados Unidos sigue siendo el destino preferido, por su cercanía, el gobierno a través de políticas públicas abre puertas a través de convenios y tratados comerciales, sin embargo; a los exportadores no les interesa diversificar, un estado de confort y codependencia comercial marcado ha envuelto a los exportadores mexicanos. Diversificar la economía implicaría tomar nuevos rumbos que suponen riesgos e incertidumbre.

México debería posicionar los intereses nacionales en el orden internacional, los cuales están orientados a obtener beneficios para acelerar y fortalecer el desarrollo nacional por medio de los TLC suscritos con ellos. En cifras la productividad total de los factores en la economía ha decrecido en los últimos 30 años a una tasa promedio anual de $0.7 \%$ el crecimiento negativo de la productividad es una de las principales limitantes para el desarrollo nacional.

La productividad en México no ha variado con dinamismo cómo consecuencia de las barreras que limitan su competitividad, "las asimétricas ventajas competitivas" de Estados Unidos merman la capacidad de México en el primer intento. A más de dos décadas de vigencia del Tratado de Libre Comercio de América del Norte (TLCAN), diversos sectores y expertos, inclusive el mismo gobierno consideró que México debe buscar la diversificación de sus exportaciones hacia las regiones con índices importantes de crecimiento, como la zona Asia-Pacífico, sin embargo; Faesler (2021) argumenta que la diversificación del comercio exterior está lejos de completarse por el atractivo del mercado vecino que ha jugado una poderosa influencia en la mentalidad del productor-exportador mexicano, restándole interés a los esfuerzos por conquistar otros mercados en América Latina, Europa, Asia y África.

Para 2021, México mantiene en vigor 13 tratados de libre comercio suscritos con 52 países, lo que le da acceso a un mercado de más de mil millones de consumidores potenciales y $70 \%$ del PIB mundial. Asimismo, ha suscrito 28 acuerdos para la promoción y protección recíproca de las inversiones con 29 países, generando certidumbre y previsibilidad entre las partes, sin embargo; se debe recalcar que aún con estos instrumentos México no cuenta con la infraestructura física acorde con su apertura internacional para facilitar la exportación e importación de bienes.

Las negociaciones comerciales internacionales son indispensables para incrementar la presencia y participación de México en los mercados globales más relevantes, esto se logrará a través de la creación de nuevas oportunidades de comercio e inversión para potenciar los flujos de inversión y comercio en América del Norte, el acceso a nuevos mercados, la consolidación de México como actor relevante, la revitalización de los vínculos comerciales y económicos y la defensa de los intereses comerciales en el exterior.

La integración comercial ha sido una prioridad para el gobierno de México desde su ingreso al GATT, y ésta no se limita a la profundización de los acuerdos o a la negociación de nuevos tratados 
comerciales, también incluye la convergencia y reestructuración de los tratados existentes, la apertura comercial que México ha logrado a través de sus acuerdos comerciales con la región ha generado una mayor venta de productos y servicios mexicanos en el exterior, además de un flujo creciente de inversiones en esos países.

Con la firma de los acuerdos comerciales no sólo se ha dado un gran paso para dinamizar el intercambio comercial y regional, sino que también se ha refrendado la relación de amistad, confianza, respeto mutuo y la cooperación con los países latinoamericanos, ejemplo de ello ha sido la Alianza del Pacifico integrada por México, Colombia, Chile y Perú. Aún y con lo anterior se debe recalcar que el entorno internacional aún no está exento de riesgos para la economía mexicana y la planeación del desarrollo nacional debe considerar puntualmente que, los factores que nos impactan son en mayor parte macroeconómicamente de índole externa que interna.

No obstante, las oportunidades de comercio en ocasiones están limitadas a algunos sectores y regiones del país, existen costos fijos en el comercio exterior que representan barreras importantes para un amplio sector productivo, la presencia de costos fijos iniciales, por la necesidad de contar con capacidad técnica y administrativa, acceso al financiamiento y asesoría, limita la diversificación del comercio exterior.

\subsection{Recursos y capacidades}

Schiavon \& Figueroa (2019) argumenta que durante la administración del presidente Enrique Peña Nieto (2012-2018) los recursos dedicados a la cooperación internacional, promoción comercial, cultural y de imagen entre otros; concluyeron en una importante baja inversión de recursos y capacidades en política exterior, estas mismas afectaron directamente la eficiencia y potencial para el seguimiento e implementación de las políticas públicas relacionadas, hubo significativa disminución de personal administrativo de la secretaría de relaciones exteriores (SRE) 820 funcionarios y trabajadores despedidos durante la administración; los recursos consulares fueron limitados además la cooperación internacional, la promoción y la diplomacia pública contando con magros recursos para su ejecución en la segunda mitad del gobierno, la reducción del presupuesto fue de $13 \%$ aproximadamente.

La Secretaría de Relaciones Exteriores (SRE o cancillería) es la institución gubernamental responsable de coordinar y ejecutar la política exterior en México Schiavon \& Figueroa (2019) argumentan que como toda institución pública, es necesario que cuente con las capacidades legales, presupuestales, de infraestructura y personal para llevar a cabo sus funciones de manera óptima, es por eso que parte del presupuesto es designado para los recursos necesarios tales como el capital humano necesario y calificado para llevar a cabo el seguimiento e implementación de las políticas públicas.

\section{ELEMENTOS QUE FORTALECEN LA GENERACIÓN DE COMPETITIVIDAD: POLÍTICAS Y ESTRATEGIAS}

De acuerdo con Porter (1990) el gobierno desempeña un papel significativo en la ventaja competitiva de los mismos y actúa como un promotor de las actividades científicas, debido a que la 
actuación del mismo país como impulsor de los determinantes de la ventaja competitiva de un país es fundamental para el desarrollo. México, independientemente del partido político que ostente el poder ejecutivo, en materia de política comercial, sigue firme y sustentando su estrategia económica internacional a través del comercio internacional, apostando sexenio tras sexenio en la diversificación con los esquemas comerciales.

Leycegui (2012) afirma que la política comercial debe estar en estrecho y permanente diálogo con las políticas que atienden los retos internos. Algunos de los principales retos internos para el autor son: aumentar la competitividad, la productividad, la eficiencia, abatir la informalidad y democratizar los beneficios del comercio internacional.

Esto apunta a trazar un plan orientado, con miras hacia los mismos objetivos, en congruencia y convergencia, parte de ello y como parte fundamental es el papel de la implementación y el seguimiento de las políticas públicas en los rubros relacionados con estos objetivos, en sintonía con las instituciones de gobierno que las llevan a cabo.

Leycegui (2012) expone que el libre comercio no es un fin en sí mismo, sino parte de una estrategia para promover el desarrollo económico y el bienestar social. Por ello, es imperativo que el comercio se empiece a medir o cuantificar de manera diferente: no en función de cuánto exportamos, sino de cuánto valor o contenido nacional agregamos a las exportaciones. Entre más valor se agregue, mayor será el impacto del comercio exterior y la inversión extranjera en la economía local, sin embargo; como afirma Ordóñez (2015) a pesar de vivir en un mundo globalizado, está en su matriz depende mucho de las condiciones sociales y económicas locales, razón por la cual para impulsar la competitividad y el desarrollo humano es necesario la implementación de políticas sociales eficientes y de la inversión del sector privado en la innovación y aplicación de tecnologías.

Según Gómez \& González (2017) desde una perspectiva macroeconómica, la competitividad se puede definir como la habilidad de una economía, en un régimen de libre mercado, para producir bienes y servicios que superen la prueba de los mercados internacionales al mismo tiempo que mantiene o mejora los niveles de ingreso real de los ciudadanos, el concepto de competitividad utilizado en el presente ensayo lo define desde el punto de vista del desempeño en el comercio internacional, y se expresa como la capacidad de un país, de una industria, de un segmento o de una cadena productiva para conquistar, mantener o incrementar su participación en los mercados nacionales e internacionales.

Por ello se debe ser eficiente en la implementación de las ventajas competitivas y comparativas en los rubros relacionados del país además de templar el propósito de las mismas, no simplemente ser el mayor exportador del mundo sino con el propósito de incrementar la productividad de calidad, mediante la competitividad, en convergencia con el fomento y la promoción de la imagen del país como un destino para la Inversión Extranjera Directa (aportaciones de inversionistas extranjeros en el capital social de la empresa, el cual forma parte del ahorro externo, contabilizado en la balanza de pagos, además de ser una fuente de financiamiento que puede aplicarse al activo circulante o al fijo), estas deben proyectar el atractivo al exterior en armonía con la triple hélice.

Según González Cháves (2015) la implementación de políticas públicas varían de un país a otro en función a sus necesidades y características específicas donde la mayor parte se concentra en la alineación de los objetivos macroeconómicos; como la creación de empleo, el desarrollo económico y el crecimiento de las exportaciones, además de objetivos sociales como la redistribución de la renta o 
ingreso y el alivio de pobreza, objetivos de eficiencia como la eliminación de externalidades, barreras de acceso al mercado.

De acuerdo con Gilpin (2001) plantea que el poder entre Estados se da más por el uso de la economía que del militarismo, por lo que, en tanto los flujos de intercambio económico de la economía de libre mercado, los Estados deben proveer la regulación y el cobro de impuestos, es decir, ciertos bienes públicos, lo anterior se logra por medio de los tratados de libre comercio.

Una segunda estrategia posibles para fomentar la innovación y la competitividad es seguir apostando por atraer la inversión extranjera directa en el país, la IED según datos de la Secretaría de Economía (2020) México captó 32,921 millones de dólares de dólares de Inversión Extranjera Directa (IED) en el 2019, un alza de 4.2\% interanual (Ver gráfica 2), siendo la manufactura, con una destacada participación del sector automotor, constituye el principal sector que atrae IED a México.

\section{Gráfica 2. Captación de Inversión Extranjera Directa (2009-2019)}

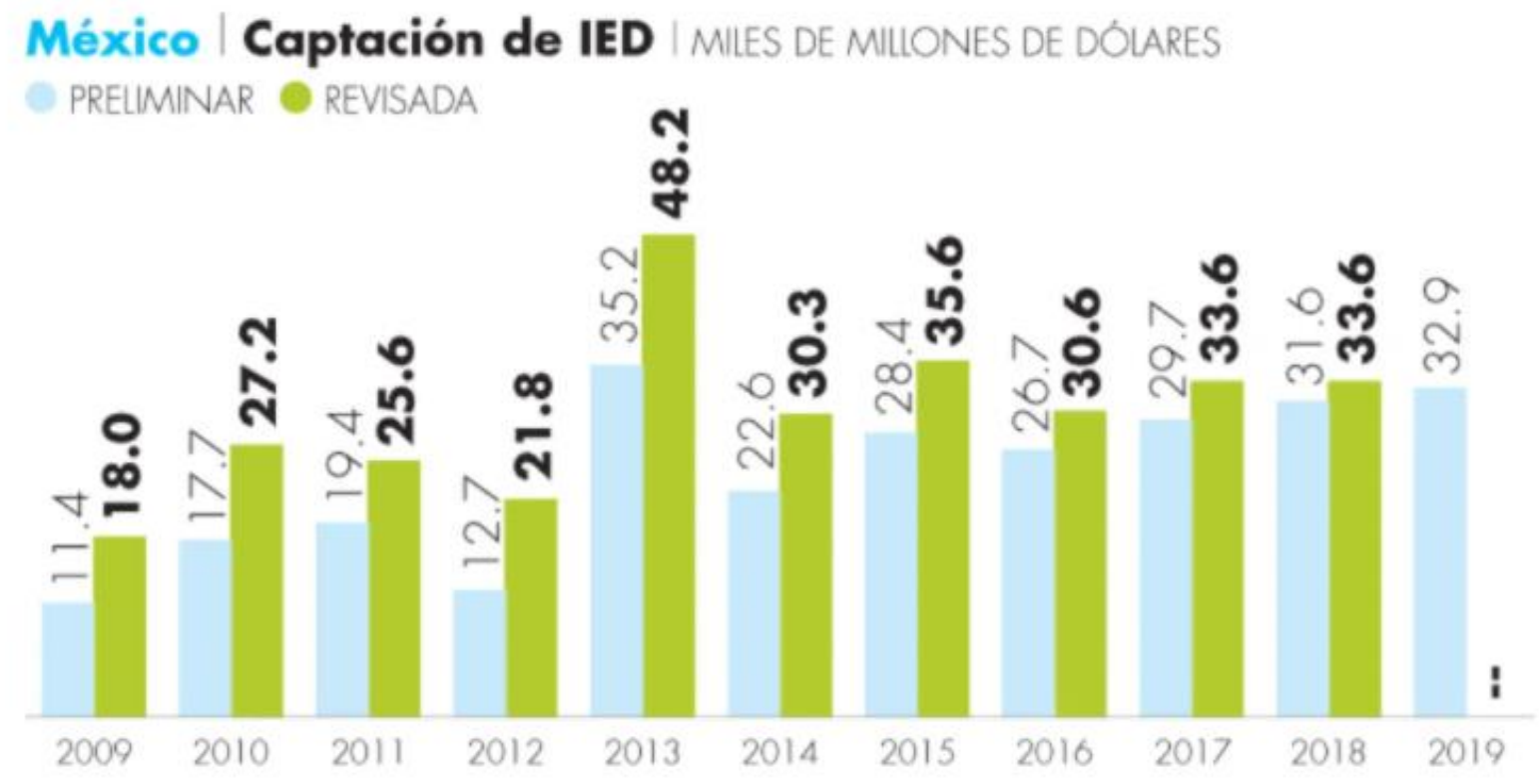

Fuente y grafica tomados de la Secretaría de Economía (2020).

Destaca que la atracción de IED ha sido funcional a la estrategia seguida y se ha convertido en uno de sus pilares macroeconómicos para solventar el déficit en cuenta corriente, esta estrategia se concretiza en múltiples acuerdos bilaterales y multilaterales, según Dussel (2000) desde una perspectiva de estrategia empresarial, la creciente IED refleja la importancia de un segmento de la economía mexicana como parte de las estrategias globales de empresas extranjeras En síntesis es una herramienta contundente para el desarrollo del país, genera estimulación en los flujos de capital y activan la economía, como dato de la evolución de la IDE en México.

Un tercer elemento que ayudaría a la competitividad es la innovación tecnológica, según Etzkowitz \& Leydesforff (2000) la innovación es el resultado de la interacción entre unidades 
económicas, Estado, actores y organizaciones científicas y académicas, lo que se conoce ahora como el modelo de la triple hélice, propuesto por los autores mencionados con anterioridad. México no es totalmente ajeno a invertir en ciencia y tecnología de acuerdo a lo mencionado por Corona (2002) afirma que la planeación de la ciencia y tecnología en México se lleva a cabo de acuerdo con los periodos presidenciales desde finales de los años 1970, cuando el INIC (Instituto Nacional de la investigación científica) formula el primer plan, con la participación amplia de la comunidad científica, el cual sirve de base para la creación del CONACYT (Consejo Nacional de Ciencia y Tecnología) siendo un precedente que marca el compromiso de México en su deseo de fomentar la ciencia y tecnología para después ser utilizado en el sector privado.

Aun así la inversión en la innovación tecnológica requiere de la voluntad no solo del ente público sino también del apoyo del sector privado de acuerdo con Solís (1995) este menciona que las circunstancias que fortalecen las medidas de libre comercio destacan el desempeño de las instituciones, la educación, las legislaciones y regulaciones por lo que es indispensable empezar con una estrategia de regulación y adecuación de estas el menor tiempo posible.

Es necesario el compromiso tanto de la administración pública como del sector privado en invertir en el crecimiento de estos sectores ya que desde la apertura comercial se han presentado diferencias competitivas entre las empresas mexicanas con las extranjeras para Máttar \& Wilson (1997) la apertura comercial ha provocado un retroceso en la sustitución de importaciones y un aumento en la desarticulación de las cadenas productivas. Además, que existe mayor desigualdad entre las empresas de niveles de competitividad consolidado (empresas grandes, con coeficientes altos de exportación, vinculación con compañías internacionales pero poca interacción con el aparato productivo) y empresas con niveles de competitividad bajo (empresas pequeñas que usan tecnología obsoleta y producen para un solo mercado interno y problemas al acceso al crédito), caracterizadas en una estructura industrial ineficiente y segmentada.

Es importante recalcar que no todos los sectores se vieron favorecidos con la apertura comercial Calderón Villarreal \& Hernández Bielma (2007) argumentan que el modelo de apertura comercial no fue favorable para el sector agropecuario, el cual se vio perjudicado por la caída de los precios agrícolas y la débil infraestructura que presenta frente al sector agrícola estadounidense, esto debido a la desventaja competitiva que presentaban las empresas mexicanos con las extranjeras, según Escalante \& González (2018), en la década de 1960 a 1970, la tasa de crecimiento promedio anual fue ligeramente superior al 4\%, sin embargo en el periodo 1981 a 1990, disminuyó hasta un promedio anual de $1.2 \%$, para después aumentar a $1.7 \%$ del año 2000 al 2010, en más de 20 años no se ha podido recuperar el dinamismo en el nivel de producción agrícola de México, esto se debe a la desprotección del sector ante la apertura comercial con Canadá y Estados Unidos.

Otra de las víctimas del TLCAN fue el de la industria del juguete según BBC Mundo (2014) con datos obtenidos de la Secretaría de Economía y de la Asociación Mexicana de la Industria del Juguete (Amiju) antes de la firma del acuerdo, más del 80\% de los juguetes que recibían los niños mexicanos eran fabricados en el país. Hoy esa cifra se ha invertido. En 1993 la AMIJU registró a 380 fabricantes, pero para 1996 el número se redujo a sólo 30, para 2014 los jugueteros mexicanos apenas comenzaron a recuperarse por medio de alianzas con empresas extranjeras, incluso chinas, y otros se convirtieron en importadores.

En términos generales el desempeño comercial mexicano para 2021 se encuentra en incertidumbre, tanto por factores internos como externos, en el ámbito externo es debido a la pandemia 
del SARS-COV-2, en el interno por el cambio de gobierno ejecutivo. Para Esquivel \& Leal, (2020) mientras que en 2019 la economía mexicana se había caracterizado, por la preservación de los fundamentos macroeconómicos (el libre comercio); se logró conseguir un nulo crecimiento lo suficiente para no entrar en recesión $(-0.14 \%)$ esto debido al estancamiento económico que se venía arrastrando desde 2018, para 2020 se pronosticó un crecimiento mínimo del 1\%, sin embargo; este tuvo un giro de timón en 2020, en el cual la economía se contrajo un $-8.5 \%$ por el impacto de la ya mencionada pandemia.

Como menciona Coutiño(2021) para lograr revertir estos resultados, es necesario que México siga apostando por la diversificación comercial y aumentar su competitividad, además su cercana relación con Estados Unidos le ayudara a recuperarse en un plazo no tan largo mientras que este siga apostando por el comercio exterior como uno de sus principales instrumentos de crecimiento.

\section{EL PROTECCIONISMO ESTADOUNIDENSE (2017-2021)}

En el verano de 2015 el republicano Donald Trump anunció su precandidatura a la presidencia de los Estados Unidos, tomando una postura económica proteccionista en contra de China y de México acusando al Tratado de Libre Comercio de América del Norte de ser el instrumento con el cual las empresas nativas americanas huían y preferían posicionarse en otros países, predicando tal discurso proteccionista venció en las elecciones presidenciales de Noviembre de 2016 a la demócrata Hillary Clinton esposa del ex presidente William Clinton quien había ratificado el TLCAN en 1993, de esta manera Donald Trump tomó posesión como presidente de Estados Unidos el 20 de Enero de 2017.

Para Leycegui Gardcuo (2012) el reto de una economía siempre será el proteccionismo frente a algún socio comercial estratégico, dicho proteccionismo cobró gran importancia con Trump y la instrumentación por parte de su Gobierno de medidas proteccionistas sustentadas en supuestos como la seguridad nacional. México sobrellevó cierto grado de incertidumbre durante la administración estadounidense de Donald Trump. El presidente criticó y calificó públicamente al TLCAN como "el peor acuerdo de la historia", las negociaciones del denominado T-MEC (antes TLCAN) fueron complicadas por la disputa de diversos intereses comerciales, la política proteccionista se percibió con fines político-electorales durante las elecciones presidenciales de 2016 y 2020.

Para los exportadores mexicanos el costo del proteccionismo estadounidense fue alto, tanto en términos económicos como políticos, uno de los ejemplos más polémicos se dio en Febrero 2018 con la aplicación del arancel global del $25 \%$ al acero y del $10 \%$ al aluminio además lo volvió a aplicar en Mayo del 2019 con el aumento del $17.56 \%$ al jitomate cuando el Departamento de Comercio estadounidense impuso el arancel luego de que ambas partes no renovaran un acuerdo anterior que mantenía suspendida una investigación por "competencia desleal" generando tensión y retrasos en los plazos de la ratificación “a posteriori”, los aranceles fueron derogados en Mayo del 2019.

Rodil (2018) menciona que las medidas de carácter proteccionista pueden volverse contra los propios intereses nacionales, debido a que las barreras a las importaciones (insumos) acaban trasladándose y afectando a las exportaciones, siendo la excusa de Trump el enorme déficit existente con México en donde para él los mexicanos han sido los más beneficiados desde 1994. 
Adicionalmente durante los cuatro años de la administración Trump (2017-2021), los exportadores, importadores y el propio gobierno federal mexicano experimento incertidumbre, roces políticos económico-sociales, imposición de aranceles que lo llevaron a ceder en varios campos a manera de mantener el flujo comerciales estable, dicho lo anterior, es necesario que México diversifique su economía, atraiga nueva inversión extranjera además de la inversión norteamericana e invierta en ciencia y tecnología para poder ser competitivo y extender su comercio a otras regiones del mundo, punto en lo que coincide Leycegui (2012) la cual argumenta que la erosión de las preferencias comerciales; la multiplicidad de las reglas de comercio; la ineficiente diversificación de los mercados, y el proteccionismo creciente desde 2017 forman parte de los principales retos exógenos que ha enfrentado México en materia de comercio internacional y a pesar de que la era del proteccionismo estadounidense ha quedado atrás de momento, es necesario que México se diversifique para no volver a pasar por las experiencias comerciales que tomaron lugar durante dicho periodo.

Rodil (2018) argumenta que la irrupción del discurso neoproteccionista estadounidense se ha apoyado en argumentos y referencias al voluminoso déficit comercial que Estados Unidos mantiene con México en el marco TLCAN y ahora en el T-MEC. No obstante, sin negar la existencia de dicho déficit, debe advertirse que este considera los flujos comerciales en bruto, sin que se preste atención al componente de valor agregado en cada territorio. Lo anterior implica una visión miope del comercio que ignora que los intercambios comerciales conllevan una amalgama de valores de origen diverso, lo cual es propiciado por la cada vez más extendida fragmentación de los procesos productivos a escala global. Dicha visión supone adoptar un enfoque equivocado de lo que realmente ocurre en el trasfondo actual de las relaciones económicas internacionales.

Aún y con el proteccionismo estadounidense implementado para Tovar (2016) México deberá continuar siendo una economía abierta incluso cuando otras se cierren, mientras procure un crecimiento que no gravite en torno a la situación de sus finanzas públicas y elimine las asimetrías de crecimiento en el interior del país.

Sin embargo, tales consecuencias son producto de la enorme dependencia mexicana generada por su relación comercial con Estados Unidos. Los actos de Trump concluyeron en la reforma del TLCAN pasando a ser ahora el T-MEC, en el cual fueron agregados regulaciones laborales, medioambientales y de comercio electrónico que en el TLCAN existían únicamente de manera parcial. Además, en base a lo mencionado por Kropiwnicka (2020) el acuerdo revisa el porcentaje del contenido de valor regional (RVC) referido a la industria del automóvil. En el TLCAN se establecía que al menos el $62,5 \%$ de un automóvil debía estar hecho con piezas procedentes de América del Norte. El TMEC eleva el porcentaje al $75 \%$ con la intención de fortalecer la capacidad de fabricación de los países y aumentar la fuerza de trabajo en la industria automotriz. Por último, se contempló que el acuerdo estaría sujeto a una revisión periódica cada seis años.

Donald Trump permaneció al frente del poder ejecutivo hasta el 20 de enero de 2021 tras ser derrotado por el demócrata Joe Biden en las elecciones presidenciales de noviembre de 2020, poniendo fin a una de las etapas más difíciles para el comercio mexicano producto de la falta de una eficiente competitividad y la poca diversificación comercial de México hacia el resto del mundo.

\section{CONSIDERACIONES FINALES}


Según la evidencia analizada y de acuerdo con los autores citados, México manifiesta deficiencia en la implementación de mecanismos que impulsan la competitividad, desde los recursos hasta el capital humano, desde la infraestructura hasta las políticas públicas para desarrollar áreas de oportunidad en la comunidad internacional. Para posicionar los intereses nacionales en el orden internacional y generar oportunidades que aceleren y fortalezcan el desarrollo nacional es necesario llevar a cabo un análisis profundo en donde los resultados de la evaluación de los factores podrán generar una visión clara de las áreas de oportunidad para la toma de decisiones con bases sólidas; en las secretarias, dependencias y áreas de gobierno permitiendo reaccionar proactivamente ante coyunturas nacionales e internacionales y por consecuencia salvaguardar la economía nacional (PIB) de un impacto negativo.

Adicionalmente durante los cuatro años de la administración Trump (2017-2021), los exportadores, importadores y el propio gobierno federal mexicano experimento incertidumbre, roces políticos económico-sociales, imposición de aranceles que lo llevaron a ceder en varios campos a manera de mantener el flujo comerciales estable, dicho lo anterior, es necesario que México diversifique su economía, atraiga nueva inversión extranjera además de la inversión norteamericana e invierta en ciencia y tecnología para poder ser competitivo y extender su comercio a otras regiones del mundo, punto en lo que coincide Leycegui (2012) la cual argumenta que la erosión de las preferencias comerciales; la multiplicidad de las reglas de comercio; la ineficiente diversificación de los mercados, y el proteccionismo creciente desde 2017 forman parte de los principales retos exógenos que ha enfrentado México en materia de comercio internacional y a pesar de que la era del proteccionismo estadounidense ha quedado atrás de momento, es necesario que México se diversifique para no volver a pasar por las experiencias comerciales que tomaron lugar durante dicho periodo.

Por último, se debe puntualizar que 2020 no ha sido un año óptimo para que México mejore en su desempeño comercial debido a la pandemia del SARS-COV-2, sin embargo; 2021 se posiciona como un año en el cual México puede volver a recuperar el ritmo perdido desde 2017 y mejorarlo implementando las medidas sugeridas en este ensayo como lo es enfocarse en eficientizar su competitividad y apostar por la diversificación comercial, aún y con esto este ensayo puntualiza en que seguir mejorando su relación con Estados Unidos pese apostar por la diversificación comercial ya que esta relación es y seguirá siendo clave para el crecimiento económico mexicano.

\subsection{De la comprobación de la hipótesis}

Procediendo a los últimos puntos del presente ensayo, se procedió a probar la hipótesis del ensayo teniendo como resultado su aceptación a través del análisis documental y explotaría que en efecto (con los datos estadísticos obtenidos en la literatura científica) ha habido un cambio significativo positivo en el modelo económico y comercial de México a partir de 1986 con su ingreso al GATT y después al convertirse en uno de los tres miembros del TLCAN, sin embargo; se debe de aclarar que este no ha sido beneficioso para todos los sectores.

\subsection{De las limitaciones}

Como últimas aclaraciones del presente ensayo, es importante señalar las limitaciones que se identificaron durante la realización de este ensayo. La primera limitante fue abarcar específicamente el 
tema desde un punto de vista meramente teórico ausentando la implementación de algún método cualitativo, o cuantitativo como entrevista a profundidad o encuesta para la obtención de datos más concretos y respaldados por la práctica.

La segunda limitante radica en que el ensayo se centró únicamente en la relación comercial México-Estados Unidos por medio del TLCAN y su posterior restructuración al T-MEC, haciendo solo una breve mención de la existencia de otros tratados comerciales, creemos que ampliar el ensayo a las demás relaciones comerciales permitirá comprender con mayor certidumbre este tema.

\subsection{De las recomendaciones}

Finalmente, el presente ensayo recomienda que, para acrecentar la literatura científica, se realicen investigaciones más concretas sobre este tema en particular, recomendando realizar un marco teórico/literario que agrupe las variables que permitan medir o validar el crecimiento o la eficiencia en un lapso concreto como ha cambiado para bien o para mal la calidad del comercio mexicano con sus socios comerciales.

Se recomienda abarcar este tema desde un punto de vista metodológico donde se aplique ya sea un método cualitativo, cuantitativo o mixto que permita conocer de manera amplia y con datos estadísticos la evolución de ciertos sectores económicos mexicanos como el automotriz o el manufacturero para conocer el impacto ya sea negativo o positivo que ha tenido sobre su competitividad desde la integración de México al comercio internacional.

\section{REFERENCIAS}

BBC Mundo. (2014). Animal Politico. Obtenido de Animal Politico: https://www.animalpolitico.com/2014/01/losganadores-y-los-perdedores-del-tlc-en-mexico-y-eu/

Calderón Villarreal, C., \& Hernández Bielma, L. (2007). El TLCAN, el empleo,los salarios y la migración internacional. En J. Mendoza Cota, El TLCAN y la frontera México-Estados Unidos: aspectos económicos (págs. 205-236). Tijuana: El colegio de la frontera Norte.

Corona Treviño, C. (2002). Innovación y competividad empresarial. Aportes, 55-65.

Coutiño, A. (21 de Enero de 2021). Expansión. Obtenido de Expansión: https://expansion.mx/opinion/2021/01/27/cuantopuede-crecer-mexico-en-2021

Duarte, E. (05 de Mayo de 2019). T21. Obtenido de T21: http://t21.com.mx/logistica/2019/09/05/logistica-esencialdiversificacion-exportaciones-mexicanas

Dussel Peters, E. (2000). La inversión extranjera en México. Santiago: Naciones Unidas.

Escalante, R., \& González , F. (2018). El TLCAN en la agricultura de México: 23 años de malos tratos. Revista Ola Financiera, 85-104.

Esquivel, G., \& Leal, J. (2020). El desempeño macroeconomico de México en 2019. Banco de México, 52-88.

Etzkowitz, H., \& Leydesforff, L. (2000). The dynamics of innovation: from National Systems and "Mode 2" to a Triple Helix of university-industry-government relations. Research Policy, 29(2), 109-123.

Faesler Carlisle, J. (2021). La diversificación del comercio exterior mexicano. Comercio Exterior Bancomext. 
Gilpin, R. (2001). Global Politic Economic:Understanding the International Economic. Princenton: Order.

Gómez Chiñas, C., \& Gomzález García, J. (2017). Competencia y competitividad de las exportaciones de México y China en el mercado estadounidense: nueva evidencia. México y la cuenca del pacífico, 79-105.

González Cháves, G. (2015). Políticas Públicas para el desarrollo y la competividad en la industria manufacturera. México: Universidad Nacional Autónoma de México. Instituto de Investigaciones Económicas Económicas.

INEGI. (27 de Diciembre de 2019). Inegi.org.m. Obtenido de Inegi.org.mx: https://www.inegi.org.mx/contenidos/saladeprensa/boletines/2019/balcom_o/balcom_o2019_12.pdf

Kropiwnicka, M. (17 de Marzo de 2020). Global Affairs. Obtenido de Globa Affairs: https://www.unav.edu/web/globalaffairs/detalle/-/blogs/diez-novedades-del-tratado-de-comercio-eeuu-mexico-canada

Leycegui Gardcuo, B. (2012). Reflexiones sobre la politica comercial internacional de México. México: Maporrua.

Máttar, J., \& Wilson, P. (1997). en Políticas de competitividad industrial en América Latina y el Caribe en los años noventa. México D.F.: Siglo XXI.

Ordóñez Tovar, J. (2015). Competitividad y bienestar en México: análisis de su relación con el desarrollo humano. Madrid: Universidad Complutense de Madrid.

Porter, M. (1990). The Competitive Advantage of Nations. The Free Press.

Rodil, O. (2018). La cara oculta del Comercio de México con Estados Unidos. Comercio Exterior Bancomex, 13.

Schiavon, J. A., \& Figueroa Fischer, J. (2019). Los recursos y capacidades de la politica exterior de México. Foro Internacional (FI), 609-642.

Secretaría de Economía. (2020). El economista. Obtenido de El economista: https://www.eleconomista.com.mx/empresas/Mexico-aumento-4.2-la-captacion-de-IED-en-2019-202002180030.html

Secretaría de Economía. (16 de Agosto de 2020). gob.mx. Obtenido de gob.mx: https://www.gob.mx/se/es/articulos/laeconomia-mexicana-recibio-un-flujo-de-ied-por-17-969-3-millones-de-dolares-durante-el-primer-semestre-de2020?idiom=es

Solis, L. (1995). Políticas Comerciales Internacionales. México: Ed. Colegio de México.

Statista. (2020). es.statista.com. Obtenido de es.statista.com: https://es.statista.com/estadisticas/616038/participacionporcentual-de-las-exportaciones-de-mercancias-por-paises-en-mexico/

Tovar Landa, R. (2016). 30 años de apertura comercial en México: del GATT al Acuerdo Comercial Transpacífico. El Cotidiano, 76-88. 